\title{
MAKNA DOA PANGROKAT DALAM TRADISI PETIK LAUT MUNCAR DI DUSUN KALIMATI BANYUWANGI
}

\author{
The Meanings of the Prayer of Pangrokat in the Muncar Sea Picking Tradition in \\ Kalimati Hamlet, Banyuwangi
}

\author{
Annisa, Juwinda, Iim Khoiria \\ Pendidikan Bahasa dan Sastra Indonesia \\ Universitas Muhmmadiyah Malang \\ Annisanisa567@gmail.com
}

Diterima 3 Juni 2019

Direvisi 25 Juni 2019

Disetujui 26 Juni 2019

\begin{abstract}
Abstrak: Penelitian ini bertujuan untuk mendeskripsikan tentang makna doa Pangrokat dalam Tradisi Petik Laut Muncar di Dusun Kalimati, Banyuwangi. Penelitian ini bersifat kualitatif, termasuk dalam penelitian etnografi dengan pendekatan semiotik. Makna yang terdapat dalam doa Pangrokat dibedakan menjadi dua makna, yaitu makna denotatif dan makna konotatif yang dipandang dari sudut semiotika. Teori semiotik yang dijadikan dasar analisis adalah teori Roland Barthes yang menjelaskan tentang tiga hal; tanda, penanda, petanda dalam mitos yang ada di dalam suatu tradisi maupun kebudayaan masyarakat. Metode yang dipergunakan dalam analisis adalah deskriptif. Hasil penelitian ini adalah adanya perbedaan pemaknaan, yakni perbedaan pemaknaan doa Pangrokat secara konotatif ditemukan, yaitu berada pada tataran kepercayaan masyarakat setempat pada tokoh-tokoh yang diyakini. Padahal secara denotatif arti yang terdapat dalam doa Pangrokat lebih mengarah kepada hal-hal yang berkaitan dengan agama Islam.
\end{abstract}

Kata kunci: Pangrokat, makna, petik laut.

Abstract: This study aims to describe the Meanings of the Prayer of Pangrokat in the Muncar Sea Picking Tradition in Kalimati Hamlet, Banyuwangi. This research is qualitative, including in ethnographic research with a semiotic approach. The meaning contained in Pangrokat prayer is divided into two meanings, namely denotative meaning and connotative meaning which are viewed from the point of semiotics. The semiotic theory which is used as the basis of analysis is Roland Barthes's theory which explains three things; signs, markers, markers in myths that exist in a tradition or culture of society (Barthes, 1972). The method used in the analysis is descriptive. The results of this study are differences in meaning. That is, the difference in meaning of the Pangrokat prayer is connotatively found, which is at the level of the trust of the local community in the figures believed. Even though the meaning denotative in Pangrokat prayer is more about Islamic matters.

Keywords: Pangrokat, meaning, petik laut.

\section{PENDAHULUAN}

Banyuwangi merupakan sebuah daerah yang terletak di ujung timur Pulau Jawa. Banyuwangi memiliki ciri khas kebudayaan yang selalu diidentikkan dengan hal magis. Salah satunya berupa teradisi Petik Laut. Masyarakat pesisir Banyuwangi, khususnya Muncar, meyakini bahwa tradisi Petik Laut mempunyai pengaruh yang besar terhadap kehidupan nelayan sehingga berkembanglah mitos dalam daerah tersebut. Mitos yang berkembang adalah adanya kepercayaan masyarakat setempat tentang adanya penjaga pantai yang bernama Nyi Roro Kidul. 
Masyarakat percaya bahwa Nyi Roro Kidul dapat menjaga mereka ketika mereka sedang mencari ikan. Berdasarkan kepercayaan itu diadakanlah ritual yang disebut Petik Laut sebagai wujud ucapan terima kasih kepada Nyi Roro Kidul.

Tradisi Petik laut dilaksanakan setiap tanggal 15 bulan Asura (penanggalan Arab), yakni di Dusun Kalimati (Djuaraan), Kecamatan Muncar. Petik Luat identik dengan gitek (miniatur perahu kecil) yang berisi berbagai-bagai sesembahan untuk roh-roh di pesisir. Roh-roh nenek moyang menjadi relasi kepada dewa untuk dimintai keselamatan dan mengendap sebagai kepercayaan di daerah tertentu.

Proses berlangsungnya pelarungan gitek diiringi pembacaan doa Pangrokat sampai pada tempat yang dituju, yaitu Watu Layar. Pembacaan doa Pangrokat ini dilakukan oleh nelayan-nelayan Desa Muncar yang dipimpin oleh ketua adat nelayan. Doa Pangrokat dipercaya sebagai syarat sah (sakral) berlangsungnya tradisi Petik Laut. Di samping itu, doa Pangrokat diwariskan turun-temurun dan sudah ada sejak dahulu melalui empat babakan waktu yang memiliki coraknya tersendiri (Soekmono, 198, hlm. 7). Dalam doa Pangrokat yang dipanjatkan terkandung makna khusus bagi masyarakat pemiliknya. Pada dasarnya pemilik doa Pangrokat merupakan masyarakat bersuku Jawa. Akan tetapi, ketika masyarakat suku Madura yang beragama Islam datang dan menetap di daerah Muncar, maka berkembanglah penggunaan bahasa dalam doa Pangrokat. Bahasa yang digunakan adalah bahasa Jawa dan Madura yang dituangkan ke dalam tulisan bahasa Arab.
Menurut Verhaar (dalam Rasyid \& Husain, 2014, hlm. 253) makna merupakan suatu hal yang berada dalam ujaran. Ujaran yang disampaikan dalam doa Pangrokat memiliki makna sendiri yang diyakini oleh penduduk setempat. Pemaknaan dalam ujaran tersebut enjadi salah satu bagian yang penting dalam keberlangsungan hidup masyarakat di pesisir Muncar.

Puisi lisan terbagi menjadi dua, yaitu puisi lisan murni dan puisi lisan tidak murni (Endaswara, 2013, hlm. 150). Doa Pangrokat merupakan puisi lisan murni karena terikat dengan tradisi setempat. Rumusan masalah penelitian ini adalah bagaimana makna doa Pangrokat dalam tradisi Petik Laut di pesisir Muncar? Penelitian ini bertujuan untuk mengetahui makna doa Pangrokat dalam tradisi Petik Laut masyarakat Muncar.

Tradisi petik laut pernah diteliti sebelumnya oleh Wulandari (2013). Tujuannya adalah untuk memberikan informasi bahwa pada masyarakat terdapat banyak bentuk sastra lisan yang disampaikan dari mulut ke mulut yang salah satunya mengenai mitos dalam upacara petik laut. Hasil penelitian yang dilakukan mendeskripsikan: (1) cerita Nyi Roro Kidul, (2) ritual upacara petik laut yang dipercaya sebagai persembahan terhadap Nyi Roro Kidul, dan 3) nilai budaya yang terkandung dalam ritual yang berkenaan dengan mitos upacara Petik Laut.

Selain hal tersebut, juga terdapat penelitian lain yang dilakukan oleh Dewi, Sendratari, dan Mudana (2014). Penelitiannya mendeskripsikan tentang: (1) latar belakang masyarakat Desa Pakutatan yang tetap mempertahankan tradisi Petik Laut dan (2) proses pelaksanaan tradisi. 
Berbeda dengan penelitian sebelumnya, penelitian ini meneliti mengenai makna doa Pangrokat. Doa Pangrokat digunakan sebagai simbol tradisi Petik Laut bagi nelayan di pesisir Muncar. Pemaknaan simbol yang mengandung nilai moral dan budaya sangat penting bagi masyarakat karena merupakan salah satu produk budaya berwujud kearifan lokal yang harus dipahami dan diresapi oleh kalangan masyarakat (Sartini, 2009, hlm. 31).

Pentingnya penelitian ini adalah untuk menjaga warisan budaya daerah setempat agar tidak hilang ditelan kemajuan zaman. Menurut Storey (dalam Ratna, 2016, hlm. 162), kebudayaaan merupakan cara pandang hidup masyarakat dalam kurun waktu tertentu. Dalam suatu kebudayaan masyarakat harus mengetahui makna yang terkandung dalam kebudayaan tersebut bukan hanya mengetahui perayaan tradisinya saja.

Pendekatan yang digunakan dalam penelitian ini adalah pendekatan semiotik dengan menggunakan teori Roland Barthes yang mengkaji suatu makna dalam simbol. Dalam teori Roland Barthes menjelaskan tatanan pertandaan denotasi yang menghubungkan antara penanda, petanda dalam tanda, sementara konotasi menjelaskan tentang interaksi tanda dengan perasaan emosional yang ada dalam budaya tertentu(Fikse dalam Rakhmat dan Fatimah, 2016, hlm. 335).

\section{KERANGKA TEORI}

Penelitian ini menggunakan teori Roland Barthes yang menjelaskan tentang tiga hal: tanda, penanda, dan petanda dalam mitos yang ada di dalam suatu tradisi maupun kebudayaan masyarakat (Barthes, 1972, hlm. 300-
303). Pemaknaan memunyai hubungan terma penanda dan petanda yang berkaitan dengan objek-objek mitos di dalamnya sebagai tanda.

Teori yang diungkapkan oleh Roland Barthes berangkat dari asumsinya yang menggap bahwa sebuah makna tidak dapat dimaknai secara tersurat saja melainkan secara tersirat juga melalui simbol-simbol yang ada (Ismujihastuti dan Mahadian, 2015, hlm. 5). Simbolsimbol tersebut memberikan sebuah makna yang lebih lengkap terhadap sebuah kajian. Simbol-simbol dalam pemaknaan tersebut berada di level penandaan tataran kedua, yaitu denotasi dan konotasi.

Menurut Roland Barthes denotasi merupakan tanda yang menghasilkan makna eksplisit, sementara konotatif merupakan tanda yang penandanya memunyai keterbukaan petanda (Piliang, 2004, hlm. 194). Penanda yang dihasilkan konotasi bersifat implisit atau tersembunyi. Barthes melihat pemaknaan yang lebih bersifat konvensional yang berkaitan dengan pemaknaan mitos. Mitos merupakan simbol makna dan nilai-nilai sosial yang dianggap sebagai sesuatu yang alamiah.

Konsep-konsep yang dikemukakan oleh Roland Barthes bersifat historis (Barthes 1972, hlm. 311). Sifat histori yang dimiliki oleh teori Roland Barthes mengakibatkan konsep mitos yang dikemukakannya tidak ada ketetapannya sehingga dapat muncul, berubah, dan bahkan benar-benar menghilang. Dalam hal ini penyebabnya adalah sebuah sejarah yang dengan sangat mudah dapat menindasnya.

Pembicaraan yang dibincangkan dalam puisi lisan doa Pangrokat, yaitu mengenai makna yang terkandung di dalamnya. Makna tersebut dapat 
diketahui melalui simbol-simbol yang terdapat dalam doa Pangrokat. Teori ini sangat berkaitan dengan pemaknaan doa Pangrokat tersebut karena di dalamnya terdapat tanda, penanada, petanda dan mitos yang memiliki sebuah makna secara tersirat.

\section{METODE PENELITIAN}

Metode penelitian yang digunakan untuk mengkaji puisi lisan doa Pangrokat dalam tradisi Petik Laut adalah metode deskriptif kualitatif karena penelitian ini bersifat kualitatif. Metode deskriptif kualitatif merupakan metode yang menghasilkan data deskriptif dalam bentuk kata-kata, baik tertulis ataupun lisan (Bogdan dan Taylor dalam Ratna, 2016, hlm. 94). Dengan demikian, penelitian kualitatif ini menemukan makna dan juga memahami makna yang ada dalam doa Pangrokat.

Puisi lisan doa Pangrokat dalam Tradisi Petik Laut dikaji dengan menggunakan pendekatan semiotik. Adapun menurut Zoest (dalam Biyantari, 2009, hlm. 11) semiotik menjelaskan tentang tanda dan juga berbagai hal yang berhubungan dengannya, cara fungsi, hubungan dengan tanda-tanda lain, serta pengiriman dan penerima-annya oleh mereka yang mempergunakan.

Sumber data dalam penelitian ini berupa dua informan, yaitu Pak Hasan dan Pak Hamidi. Alasan memilih Pak Hasan sebagai informan karena beliau merupakan Ketua Himpunan Nelayan seluruh Indonesia, sedangkan Pak Hamidi adalah seorang ketua adat di desa Muncar. Data tersebut berupa doadoa pernyataan dari informan yang diucapkan secara lisan.

Teknik pengumpulan data dari penelitian ini menggunakan wawancara dan juga observasi tempat. Wawancara (interview), yaitu jenis teknik pengumpulan data dengan cara mengajukan pertanyaan secara langsung yang dilakukan oleh pewawancara (pengumpul data) kepada infoman dan jawaban-jawaban narasumber direkam dengan alat perekam (Soehartono, 2015, hlm. 67-68), sedangkan observasi atau pengamatan ialah suatu tindakan pengukuran dengan melibatkan alat indra yang berarti tidak mengajukkan pertanyaan-pertanyaan. Peneliti melakukan cara observasi agar mengetahui tempat yang digunakan untuk penelitian.

Teknik analisis data dalam penelitian ini menggunakan metode etnografi. Adapun langkah yang digunakan untuk menganalisis sebagai berikut: (1) Menerjemahkan doa pangrokat dari bahasa arab pegon; (2) Pengelompokkan data berdasarkan data yang akan diteliti; (3) Mendeskripsikan makna doa pangrokat yang terdapat pada data; (4) Menarik kesimpulan dan digunakan sebagai keabsahan data.

Mengecek keabsahan data dilakukan dengan triangulasi. Dalam hubungannya dengan triangulasi, terdapat empat cara untuk menguji validasi data dalam penelitian ini, yaitu membandingkan hasil pengamatan, membandingkan pengakuan informan, dan membandingan pendapat saat dilakukan penelitian.

Dalam makna doa Pangrokat yang sesungguhnya (yang dikaji) dengan makna yang dipercayai mengalami perbedaan yang kontras. Makna secara mitos yang berlaku lebih menekankan pada cerita zaman dahulu yang diturun dari nenek moyang dan tidak di ketahui kevaliditasnya. Sementara secara pengartian dari doa Pangrokat yang dikaji 
lebih menekankan nilai-nilai Islami dan wujud rasa syukur.

\section{HASIL DAN PEMBAHASAN}

Berdasarkan kajian yang telah dilakukan terdapat makna doa Pangrokat dalam tradisi Petik Laut di pesisir Muncar. Makna tersebut diuraikan berdasarkan tanda, penanda, dan petanda yang ditemukan dalam data. Makna doa Pangrokat tersebut berupa makna secara denotatif dan konotatif.

Menurut Hasan Basri selaku ketua Himpunan Nelayan Seluruh Indonesi (HNSI) menjelaskan proses upacara tradisi Petik Laut yakni sebagai berikut.

1) Pembentukkan panitia upacara tradisi Petik Laut.

2) Persiapan gitek, gitek adalah miniatur perahu yang berisi sesajen atau sesembahan.

3) Satu hari sebelum pelarungan gitek dilakukan ider bumi, ider bumi adalah pembawaan gitek keliling kampung mulai pukul 14.00-17.00 WIB.

4) Istigosah (tirakat) dilakukan semalam hingga pukul 02.00 dini hari.

5) Pembacaan mamaca, mamaca adalah menceritakan nilai-nilai kenelayanana yang dilagukan dalam ajaran agama Islam sesuai dengan tema.

6) Hari pelarungan ditandai dengan pembukaan yaitu pengguntingan pita oleh Bupati Banyuwangi.

7) Pengantaran gitek ke pelabuhan pukul 07.00 pagi dengan diiringi papakan yaitu unen-unen cakcaan. Papakan merupakan sejenis kejungan khas nelayan Madura.

8) Sambutan dilanjutkan dengan tarian gandrung yaitu jejer gandrung.

9) Gitek dibawa menuju Watu layar menggunakan perahu secara beramairamai dengan diiringi pembacaan doa Pangrokat, pembacaan doa tersebut dilakukan berkali-kali, sekitar pukul 09.00-11.00 siang sampai ke tempat tujuan

10)Gitek sampai di pujuk (makam) gandrung di Sembulungan dan dibacakan solawat, lalu dilepaskan ke laut. Proses pelaksanaan upacara tradisi Petik Laut pun selesai.

\section{Makna Denotatif Doa Pangrokat}

Dalam pembacaan doa Pangrokat menggunakan tiga bahasa, yaitu Arab, Jawa, dan Madura. Penggunaan tiga bahasa tersebut menimbulkan makna secara denotatif. Pemaknaan denotatif digambarkan dengan pengucapan dan penulisan dengan bahasa Arab pegon dan Jawa. Kutipan doa Pangrokat berikut diperoleh dari infroman yang bernama Hasan Basyri dan Hamida.

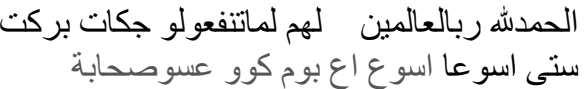

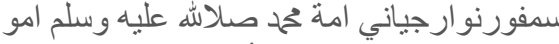

$$
\begin{aligned}
& \text { نب ور اكى فونجا بحيا بن أيلامتاكسامة محمد اوليا }
\end{aligned}
$$

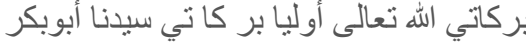

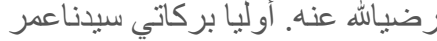

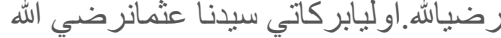

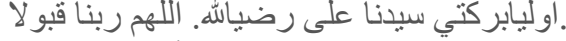

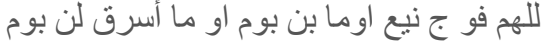

$$
\begin{aligned}
& \text { اسرف فوزف } \\
& \text {.رزقي سلامة جكت تو تونفو فو لاه الحمدله } \\
& \text { اللهم دفع عنا البلاء تهاء }
\end{aligned}
$$

Artinya: segala puji bagi Allah Tuhan semesta alam. Manusia sebaiknya bangga jika diberkati.

Sitik suwung ing bumi kawuh sahabat sampun ajeni umur Muhammad (Menghormati umur Muhammad yang berada di bumi hanya sebentar saja).

Pertama-tama berkati Allah dan pertama lagi berkati Nabi Muhammad. Kabulkanlah doa kami. Pertama berkatilah Abu 
Bakar r.a. Pertama berkatilah Saidina Ali r.a. Kabulkanlah doa kami.

Pertama berkatilah Siti Fatimah istri Rasulullah Saw. dan berkatilah Saidina Hasan dan Husein r.a. Ya, Allah, ya, Tuhanku utamanya berkatilah Nabi Ishak.

Pertama berkatilah Nabi Sulaiman. Pertama berkatilah Baginda Hamzah. Pertama berkatilah Nabi Ayub. Pertama berkatilah Nabi Ilyas dan Qidir. Terimalah doa kami.

Berkatilah Kyai Abdullah bin Abdul Muthalib. Berkatilah Aminah Abdullah. Terimalah doa kami. Berkatilah Yahud bin Rubil dan Samaun ra. Terimalah doa kami. Berkatilah Syech Jaelani dan berkatilah Nabi Yusuf beserta Nabi Ismail dan Rubbil ra.

Terimalah doa kami.

Pertama berkati syafaat malaikat rohaniah. Poro (para) malaikat Allah. Berkatilah utusan Allah Nabi beserta Rasulnya. Berkatilah rizki kami. Ya Allah ya Tuhanku pujining umat bin bumi umat Assura lan bumi Assura rizki ingkang salamah jagat. Balak lan Wabak.

Berdasarkan data tersebut ditemukan beberapa tanda yang menjadi penanda dari makna secara denoatif pada doa Pangrokat. Dalam teorinya, Roland Barthes berpendapat bahwa sebuah makna yang dihasilkan berupa makna yang bersifat eksplisit dan implisit. Adapun data yang menunjukkan adanya makna eksplisit sebagai berikut:
"Segala puji bagi Allah Tuhan semesta alam. Manusia sebaiknya bangga jika diberkati."

Berdasarkan data tersebut, kalimat Tuhan Semesta Alam adalah tanda yang dijadikan sebuah penanda dalam pemaknaan secara denotatif. Makna yang terkandung dalam tanda tersebut adalah mengakui kebesaran tuhan sebagai pemilik semesta alam sehingga dianggap sebagai wujud yang paling agung.

"Sitik suwung ing bumi kawuh sahabat sampun ajeni umur Muhammad."

Arti dalam bahasa Indonesia: "Cukup tenang di bumi dilakukan dengan baik oleh para sahabat (Nabi Muhammad) yang menghormati umur Nabi Muhammad."

Berdasarkan data pada kalimat ajeni umur Muhammad merupakan tanda dari sebuah penanda dalam pemaknaan secara denotatif. Makna yang terkandung ialah wujud penghormatan terhadap Nabi Muhammad. Adapun ketika seseorang menghormati Nabi Muhammad maka seseorang itu akan mendapatkan hidup yang tenang di bumi manusia.

"Pertama-tama berkati Allah dan pertama lagi berkati Nabi Muhammad. Kabulkanlah doa kami. Pertama berkatilah Abu Bakar ra. Pertama berkatilah Saidina Ali ra. Kabulkanlah doa kami."

Berdasarkan data pada kalimat berkati/berkatilah merupakan tanda dari sebuah penanda doa Pangrokat dalam 
pemaknaan secara denotatif. Makna yang terdapat dalam kata berkati adalah merasa syukur karena telah diberi berkah dari Allah, Nabi Muhammad, Abu Bakar sahabat Nabi dan Ali sahabat nabi.

"Ya Allah ya Tuhanku pujining umat in bumi umat Asyura lan bumi Asyura rizki ingkang salamah jagat. Balak lan Wabak."

Arti dalam bahasa Indonesia: "Ya Allah ya Tuhanku hormatnya masyarakat di bumi dan masyarakat di bulan asyura atas rizki besar yang didapatkan melewati antara kesialan dan tercemarnya penyakit."

Berdasarkan data pada kalimat pujining umat in bumi merupakan tanda dari sebuah penanda dalam pemaknaan secara denotatif. Makna yang terkandung ialah menghargai manusia yang ada di bumi. Ketika seseorang menghormati sesama manusia yang ada di bumi manusia juga menghormati bulan Asyura sebagai bentuk pemberian rezeki pada bulan tersebut serta agar manusia terhindar dari mara bahaya yang ada di dunia.

Doa Pangkrokat dibaca berkali-kali seperti orang berdzikir. Meminta pertolongan kepada orang tua zaman dahulu untuk keselamatan dan rezeki. Doa Pangrokat ini untuk mengungkapkan rasa syukur terhadap Allah Swt. yang menciptakan laut dan bumi semesta. Bulan Asyura ini digunakan untuk pelaksanaan pembacaan doa Pangrokat.

\section{Makna Konotatif Doa Pangrokat}

Dalam doa Pangrokat terdapat makna secara kontatif. Menurut Roland Barthes, penanda yang dihasilkan konotasi bersifat implisit atau tersembunyi.
Barthes melihat pemaknaan yang lebih bersifat konvensional yang berkaitan dengan pemaknaan mitos. Dalam kutipan doa Pangrokat berikut terkandung makna secara konotatif yang masih digunakan masyarakat setempat sebagai kepercayaan mereka.

Ya Tuhan kami sangat merasa bangga ketika kami meminta berkat darimu. Menghormati umur Muhammad yang hanya sebentar berada di bumi. Jauhkanlah kami dari sesuatu hal yang buruk yang dapat mencelakai kami. Ya Allah, Tuhanku kabulkanlah dan terimalah doa kami.

Pertama-tama berkatilah Abu Bakar, Umar bin Khatab, Usman bin Affan, Ali bin Abu Tolib. Ya Allah, Tuhanku kabulkanlah dan terimalah doa kami. Pertama-tama berkatilah Siti Fatimah (istri Rasulullah). Ya Allah, Tuhanku kabulkanlah dan terimalah doa kami. Pertama-tama berkatilah Hasan dan Husein.

Berikut percakapan antara informan (Hamida) Maret 23, 2018 dan penulis terkait dengan makna doa Pangrokat. Makna doa Pangrokat yang diyakini masyarakat setempat sebagai berikut.

P: Apa makna yang terkandung dalam doa pangokat?

I: Ya doanya itu mengndung makna rasa syukur terhadap Allah, para Nabi, dan juga Nyi Roro Kidul

Berdasarkan data tersebut ada juga juga hasil wawancara yang telah penulis lakukan bahwa masyarakat meyakini makna doa Pangrokat sebagai wujud syukur dan bentuk penghomatan. Rasa syukur terhadap Allah, para nabi, dan Nyi Roro Kidul. Agar ikan-ikan tetap banyak, agar nelayan mendapatkan banyak ikan, agar diberi keselamatan saat sedang melaut. 
Dalam wawancara yang dilakukan, Hamida menjelaskan tentang filosofi cerita pada zaman dahulu tentang doa Pangrokat yang diwariskan turuntemurun dengan orang-orang pilihan. Menurut keyakinan secara turuntemurun doa yang dipanjatkan tersebut adalah bentuk rayuan terhadap Sang Penguasa agar selalu menjaga alam terutama lautan sehingga bisa bersahabat dengan mereka dalam menjalani kehidupan.

Ucapan meminta berkah kepada para nabi merupakan wujud penghormatan karena telah menghantarkan masyarakat pada kehidupan sejahtera seperti sekarang. Masyarakat setempat percaya bahwa tanpa perjuangan Nabi Muhammad masyarakat tidak bisa merasakan kedamaian hidup. Masyarakat juga meyakini bahwa Nabi Muhammad merupakan kekasih yang selalu dekat dengan Allah.

Seorang informan, yaitu Hamida menjelaskan juga tentang berkah yang dilimpahkan yang ditujukan kepada empat tokoh kepercayaan yang diyakini dan terlibat dengan lautan. Tokoh-tokoh tersebut, yaitu: (1) Nyi Roro Kidul yang menyiratkan kekuatan magis di dalam lautan, serta merupakan penguasa laut. Penguasa laut yang miliki lautan dan segala isi di dalamnya. Isi lautan berupa ikan-ikan yang dikehendaki nelayan sebagai mata pencaharian para nelayan. Masrayakaat meyakini dengan adanya Nyi Roro Kidul si penguasa lautan, maka para ikan di dalamnya akan dijaga. Agar ikan selalu ada, agar ikan selalu banyak, sehingga nelayan dapat memperoleh ikan dengan banyak keuntungan. Tokoh Nyi Roro Kidul merupakan salah satu tokoh dari cerita Legenda yang banyak diperbincangkan oleh masyarakat setempat maupun masyrakat di luar
Muncar. Cerita legenda tersebut tersebar tidak hanya di Muncar saja, melainkan di berbagai tempat di belahan pantai selatan. Akan tetapi, masyarakat Muncar menyakini tokoh tersebut karena adanya upacara tradisi Petik Laut.

Padahal secara arti denotatif doaPangrokat, tidak menyebutkan tokoh Nyi Roro Kidul di dalamnya. Penguasa laut dan segala isi lautan di dalamnya merupakan ciptaan Tuhan yang Maha Esa. Seperti dalam suatu penanda di dalam arti doa Pangrokat, yaitu Segala puji bagi Allah Tuhan semesta alam yang berarti semua yang ada di dunia ini merupakan milik Tuhan dan tidak dapat dipungkiri keberanya. Ikan yang para nelayan dapatkan merupakan usaha nelayan itu sendiri dan kehendak Tuhan saat sedang menjala. Ikan tetap ada dan banyak di lautan karena kesehatan laut. Banyaknya terumbu karang, anak-anak ikan tetap dijaga dan tidak ditangkap, serta tidak membuang segala macam limbah di lautan merupakan usaha yang harusnya diyakini oleh masyarakat setempat agar ikan selalu ada dan mendapatkan keuntungan ketika sedang bekerja.

Adapun menurut informan, yaitu Hamida terdapat juga mitos yang diyakini tentang Nyi Roro Kidul. Ada perkataan, jika semua sesajen atau sesembahan dan doa yang dipanjatkan tidak sesuai, akan ada malapetaka bahaya yang datang. Malapetaka tersebut dapat membuat seorang anak manusia hilang ataupun ditemukan meninggal di laut. Akan tetapi, segala mitos yang dipercayai tersebut seiring bergantinya generasi tidak lagi begitu dipercayai. Hanya orang-orang tertentu yang masih memercayai mitos-mitos tersebut. 
Sementara arti denotatif dalam doa Pangrokat menyebutkan kalimat Balak lan Wabak yang merupakan penandaan. Artinya bahwa mara bahaya di dalam doa Pangrokat disebut musibah atau kesalahan manusia yang dikehendaki oleh Tuhan untuk terjadi, bukan dari tokoh Nyi Roro Kidul seperti yang diutarakan informan. Perbedaan arti dengan mitos merupakan keyakinan dari masyarakat setempat yang tidak dapat dihilangkan begitu saja.

(2) Nabi Hidir merupakan nabi yang dipercayai memiliki kekuasan untuk memunculkan ikan di lautan dan mempermudah nelayan untuk mendapatkan ikan dengan banyak. Hal itulah yang membuat masyarakat setempat sangat menghargai tokoh tersebut.

(3) Nabi Nuh merupakan nabi yang dalam kisah teladan menyimbolkan bahwa Nabi Nuh si pembuat perahu pertama di dunia untuk menyelamatkan makhluk-makhluk Allah akan banjir besar pada masa itu dan difilosofikan oleh masyarakat bahwa Nabi Nuh merupakan penjaga perahu. Menjaga nelayan dari ombak dan mara bahaya di lautan dan di lindungi oleh perahu yang diyakini dijaga oleh Nabi Nuh.

(4) Raden Marsodo merupakan salah satu tokoh yang yang memiliki pengaruh besar terhadap keyakinan masyarakat pesisir Muncar. Raden Marsodo diyakini oleh masyarakat sebagai nelayan pertama yang mencari ikan di pesisir pantai Desa Muncar. Ia orang pertama yang mengunakan pancing untuk menangkap ikan dan sanggup berlayar jauh. Melihat keberanian yang dilakukan oleh Raden Marsodo membuat masyarakat menjadi ingin melakukannya juga. Sejak saat itu masyarakat pesisir Muncar mulai mengenal pancing dan mulai menangkap ikan menggunakan alat tersebut.

Banyak mitos yang beredar terkait tokoh Raden Marsodo. Menurut Hamida, pada zaman dahulu dipercaya Raden Marsodo menangkap ikan dengan pancing emas nomor sembilan dengan batang pancing yang terbuat dari rotan dan diambil dari pantai Pulau Merah. Melihat perlengkapan yang digunakan oleh Raden Marsodo begitu berbeda dengan umumnya membuat masyarakat setempat semakin meyakini bahwa Raden Marsodo memiliki pengaruh yang besar dalam kegiatan menangkap ikan mereka. Raden Marsodo hingga saat ini masih tetap diyakini oleh masyarakat setempat. Hal itu dibuktikan dengan ritual yang dilakukan masyarakat setiap tahunnya. Ritual yang dilakukan masyarakat sebagai wujud dari kepercayaan mereka yakni ritual Petik Laut. Masyarakat Muncar melakukan ritual Petik Laut menggunakan sesajen. Sesajen yang diberikan dilengkapi dengan yang dipakai oleh Raden Marsodo. Hal tersebut dianggap masyarakat setempat sangat perlu dilakukan agar Raden Marsodo mengetahui bahwa sesajen itu ditujukan untuk dirinya.

Perbedaan antara arti dalam doa Pangrokat dengan mitos-mitos di dalamnya inilah yang menjadi suatu hal yang patut diketahui. Masyarakat pemilik mitos menyakini suatu mitos tersebut tidak dapat dipisahkan dari kehidupan bermasyarakat yang sudah terjalin sejak sangat lama. Akan tetapi, mitos tidak selamanya dapat dipercayai keutuhan-nya, dilihat dari berkembangnya zaman dan mengubah pola pandang generasi yang mendatang. Tidak dapat dipungkiri jika mitos akan selalu melekat dalam kehidupan 
masyarakat Muncar karena upacara tardisi Petik Laut begitu disakralkan dan terus dilakukan beserta keyakinankeyakinan di dalamnya. Mengingat doa Pangrokat diwariskan secara turuntemurun dengan orang-orang pilihan tertentu.

Alasan masyarakat setempat masih memercayai tokoh-tokoh Nyi Roro Kidul dan Raden Marsoda atau mitos-mitos di dalamnya karena hal tersebut sudah sejak lama dan para leluhur berkata begitu. Tidak ada alasan pasti, bahkan seorang informan, yaitu Hamida hanya menyebutkan kalau mitos-mitos tersebut sudah ada sejak dahulu kala dan merupakan warisan nenek moyang yang tidak dapat ditinggalkan begitu saja. Atas dasar nenek moyang, masyarakat setempat masih memercayai hal tersebut. Akan tetapi, seiring dengan pergantian generasi hal semacam itu lambat laun tidak dapat dipercayai lagi untuk kebenarannya bagi sebagian masyarakat.

\section{PENUTUP}

\subsection{Simpulan}

Pada dasarnya setiap daerah memiliki ciri khas kebudayaannya masing-masing. Salah satunya adalah kebudayaan yang berasal dari Kabupaten Banyuwangi, Kecamatan Muncar yang menyakini hal-hal magis. Kebudayaan tersebut dikenal dengan upacara tradisi Petik Laut yang di dalamnya terdapat doa Pangrokat yang dianggap sebagai suatu hal sakral dalam ritual tersebut.

Doa Pangrokat menggunakan tiga bahasa dalam pengartiannya, yaitu bahasa Jawa, bahasa Madura, dan bahasa Arab. Akan tetapi, saat diucapkan dalam upacara tradisi Petik Laut menggunaan pelafalan bahasa Arab.
Pemaknaan dalam doa Pangrokat meliputi dua makna, yaitu: (1) makna denotatif dalam doa Pangrokat berupa pengartian atau terjemahan dari doa Pangrokat tersebut ke dalam bahasa Indonesia. (2) makna konotatif dalam doa Pangrokat berupa gabungan dari makna denotatif dengan mitos yang diyakini oleh masyakarat setempat. Akan tetapi, hasil penelitian menemukan antara makna dengan mitos mengalami perbedaan yang kontras.

Perbedaan yang ditemukan dalam doa Pangrokat, yaitu terletak pada kepercayaan masyarakat setempat pada tokoh-tokoh yang diyakini. Padahal secara denotatif, arti yang terkandung dalam doa Pangrokat tentang hal-hal yang berkaitan dengan keislaman yang tidak ada keterkaitannya dengan tokohtokoh yang diyakini masyarakat tersebut seperti, Nyi Roro Kidul dan Raden Marsodo. Akan tetapi, doa yang dipanjatkan memiliki tujuan yang sama, yaitu permohonan rasa syukur, meminta berkah dan keselamatan.

\section{DAFTAR PUSTAKA}

Barthes, R. (1972). Membedah Mitos-Mitos Budaya Massa: Semiotika atau Semiologi Tanda, Simbol, dan Representasi. (Ikramullah, M., penerjemah).Yogyakarta: Jalasutra.

Biyantari, L. A. (2009). Aspek Moral dalam Novel Harimau! Harimau Karya Mochtar Lubis Tinjauan Semiotik. Skripsi. Program Sarjana Universitas Muhammadiyah Surakarta, diperoleh dari http:/ / eprints.ums.ac.id/id/eprint /4443. 
Dewi, I. A. K. S., Sendratari, L. P., \& Mudana, I. W. (2014). Pemertahanan tradisi budaya petik laut oleh nelayan Hindu dan Islam di desa Pekutatan, Jembarana-Bali. Widya Winayata: Jurnal Pendidikan Sejarah, 2(1), 1-12, diperoleh dari https:/ / ejournal.undiksha.ac.id/ind ex.php/JJPS/article/view/4153.AD DIN Mendeley Bibliography CSL_BIBLIOGRAPHYXEndaswara, S. (2013). Metode Penelitian sastra (epistemologi, model, teori, dan aplikasi). Yogyakarta: Media Press.

Ismujihastuti, R. A. G. D., \& Mahadian, A. B (2015). Representasi wanita dalam sampul album raisa (analisis semiotik roland barthes terhadap sampul album raisa andriana "raisa" dan "heart to heart"). eProceedings of Management,2(1), 9941007, diperoleh dari https:/ / libraryeproceeding.telkomu niversity.ac.id/index.php/manage ment/article/view/3444/3268.

Piliang, Y. A. (2004). Semiotika teks: Sebuah pendekatan analisis teks. MediaTor Jurnal

Komunikasi, 5(2), 189-198. doi:10.29313/mediator.v5i2.1156.

Rakhmat, P., \& Fatimah, J. M. (2017).Makna Pesan simbolik non verbal tradisi mappadendang di kabupaten Pinrang. KAREBA: Jurnal
Ilmu Komunikasi, 5(2), 331-348. doi: 10.31947/kjik.v5i2.1911.

Ratna, N.K. (2016).Metode penelitian kajian budaya dan ilmu-ilmu sosial humaniora pada umumnya. Yogyakarta: Pustaka Pelajar.

Sartini, N. W. (2009). Menggali Nilai kearifan lokal budaya jawa lewat ungkapan (bebasan, saloka, dan paribasa).Logat: Jurnal Ilmiah-Ilmiah Bahasa Dan Sastra, 5(1), 28 -37.

Soekmono, R. (1981). Pengantar sejarah kebudayaan Indonesia 3. Yogyakarta: Penerbit Kanisius.

Soerhartono, I. (2015). Metode penelitian sosial suatu teknik penelitian bidangkesejahteraan sosial dan ilmu sosial lainnya. Bandung: PT Remaja Rosdakarya.

Rasyid, S., \& Husain, M. (2014). Puisi magis pangissengeng: Bentuk dan makna. Sawerigading, 20(2), 251-259. doi: 10.26499/sawer.v20i2.31.

Wulandari, W. (2013).Mitos dalam upacara petik laut masyarakat madura di Muncar Banyuwangi: Kajian etnografi.Skripsi. Program Sarjana Universitas Negeri Jember, diperoleh dari http://repository.unej.ac.id/handle /123456789/3819. 